\title{
An equilibrium analysis of the gender wage gap
}

\author{
Graciela CHICHILNISKY* \\ and Elisabeth HERMANN FREDERIKSEN **
}

\begin{abstract}
Within a two-sector general equilibrium model, women's productivity in the marketplace decreases with the amount of household work they perform at home. Assuming that men's and women's household labour inputs are complementary here we prove the existence of multiple equilibria. In some, men and women allocate their labour equally and earn identical wages. In others, they allocate labour differently and earn different wages. In this context, beliefs about the inferiority of women's productivity are shown to be self-fulfilling. By use of numerical examples, we show that welfare is highest when spouses allocate labour equally and suggest policy recommendations.
\end{abstract}

emale labour-force participation has increased substantially during the past half century in advanced economies (Fullerton, 1999). In addition, women's educational achievements are rising. In the United States, women have overtaken men as the most educated sex since the mid-1990s (Freeman, 2004). Nevertheless, despite these advances in women's labour-force position, and

* Columbia University, email: gc9@columbia.edu.** University of Copenhagen, EPRU, and FAME, email: ehf@econ.ku.dk.

Many thanks to the editor and anonymous referees of the $I L R$ for helpful comments and suggestions. Also many thanks to Christian Groth, Christian Schultz, Mich Tvede, and seminar participants in the EPRU seminar at the University of Copenhagen and at the 2004 annual DGPE workshop for their helpful and productive suggestions. The research was supported by the Danish Social Science Research Council, by the Danish Ministry for Food, Agriculture, and Fisheries, and by the Danish Agricultural and Veterinary Research Council. The authors thank the Program on Information and Resources (PIR) at Columbia University for supporting this research and Dr. Frederiksen's visit to Columbia University. Correspondence: Elisabeth Hermann Frederiksen, Department of Economics, University of Copenhagen, Studiestræde 6, 1455 Copenhagen-K, Denmark.Email: ehf@econ.ku.dk.

Responsibility for opinions expressed in signed articles rests solely with their authors and publication does not constitute an endorsement by the ILO. 
despite the adoption of "equal work/equal pay" regulations in many countries, ${ }^{1}$ women do not seem to be earning the same pay as men.

Ever since women entered the labour force, the gender wage gap has been closing. ${ }^{2}$ In the United States, the gap narrowed in the 1980s after a stable period following the 1960s (Blau and Kahn, 2000). Since then the convergence of male and female wages has slowed. In the United States, the gender wage gap has remained almost constant since the early 1990s (Blau and Kahn, 2006). Similar findings are presented for other advanced economies, such as Sweden's (Edin and Richardson, 2002) and Denmark's (Datta Gupta, Oaxaca and Smith, 2006). In the OECD countries, on average, women earn 84 per cent of men's hourly earnings (OECD, 2002). ${ }^{3}$

Concurrently with the gender wage gap, today's division of labour between spouses within the household appears surprisingly traditional. In advanced economies, time-use studies consistently show that wives spend relatively more time in home production than do husbands, and that husbands spend relatively more time in the workplace than do wives (Bonke, Datta Gupta and Smith, 2005; Freeman and Schettkat, 2005; Short 2000). In their elaborate empirical study, Davis, Greenstein and Gerteisen Marks find that "with no exception in all 28 nations women perform more household work than men" (2007, p. 1259). ${ }^{4}$ As shown in table 1, women do 2-3 times more household work than do men in modern societies, a ratio which is confirmed by Coltrane (2000) and others. Yet, men and women roughly spend the same total amount of time on the two activities - market and household work - taken together (Freeman and Schettkat, 2005).

Figure 1 is a scatter plot of the wage gap against the (self-reported) male share of household work across a sample of advanced economies. The plot suggests a negative correlation, albeit not a significant one. 5 The less men participate in the household work, the greater the difference between male and female pay in the market place.

The purpose of this article is to propose a theory that can explain the persistence of male-female differences in wages and time allocation in modern societies and to examine its welfare properties. We build on the strand of litera-

1 The ILO's Equal Remuneration Convention, 1951 (No. 100) has been ratified by 162 countries (http://www.ilo.org/ilolex/english/convdisp2.htm). In the United States, some states have enacted equal pay legislation (for example, New York), but the country as a whole still does not have an equal pay law.

2 In general, the gender wage gap is a rough estimate that includes both differences in earnings across "male and female occupations" and differences in male and female earnings within the same occupation. One should therefore be careful when comparing wage gap estimates from different sources.

3 There is some evidence, however, that new cohorts of women fare better than previous ones (Blau and Kahn, 2000).

${ }^{4}$ Davis, Greenstein and Gerteisen Marks (2007) base their empirical findings on data from 17,636 respondents in 28 countries.

5 The intercept estimate is 25.95 (2.97) and the slope estimate is $-0.29(-1.08)$ of the corresponding regression, the numbers in parentheses being $t$-statistics. The fraction of the variation in the wage gap explained by the regression is 8 per cent $\left(R^{2}\right.$ is 0.08$)$. 
Table 1. Allocation of daily work hours between the home and the workplace

\begin{tabular}{|c|c|c|c|c|c|c|c|}
\hline & \multicolumn{2}{|l|}{ Market } & \multicolumn{3}{|l|}{ Home } & \multicolumn{2}{|l|}{ Total } \\
\hline & Women & Men & Women & Men & Ratio $^{a}$ & Women & Men \\
\hline Austria & 7.9 & 9.8 & 3.7 & 1.3 & 2.8 & 11.6 & 11.1 \\
\hline Canada & 8.5 & 9.6 & 2.8 & 1.7 & 1.6 & 11.3 & 11.3 \\
\hline Italy & 6.5 & 7.9 & 4.0 & 0.9 & 4.4 & 10.5 & 8.8 \\
\hline Netherlands & 4.1 & 6.7 & 4.0 & 2.0 & 2.0 & 8.1 & 8.7 \\
\hline Norway & 7.2 & 8.7 & 3.4 & 2.1 & 1.6 & 10.6 & 10.8 \\
\hline United Kingdom & 6.9 & 8.8 & 3.3 & 1.3 & 2.5 & 10.2 & 10.1 \\
\hline United States & 8.4 & 9.3 & 2.5 & 1.5 & 1.7 & 10.9 & 10.8 \\
\hline
\end{tabular}

ture which includes Becker's (1985) seminal work on sexual division of labour, Chichilnisky (2005) and Chichilnisky and Eisenberger (2005). In Becker (1985), as a result of increasing returns to specialization gains in at least one sector, spouses gain from a division of labour between employment and household work. This leads to a gender wage gap, which is Pareto efficient. Chichilnisky

Figure 1. Correlation between the gender wage gap and male share of housework

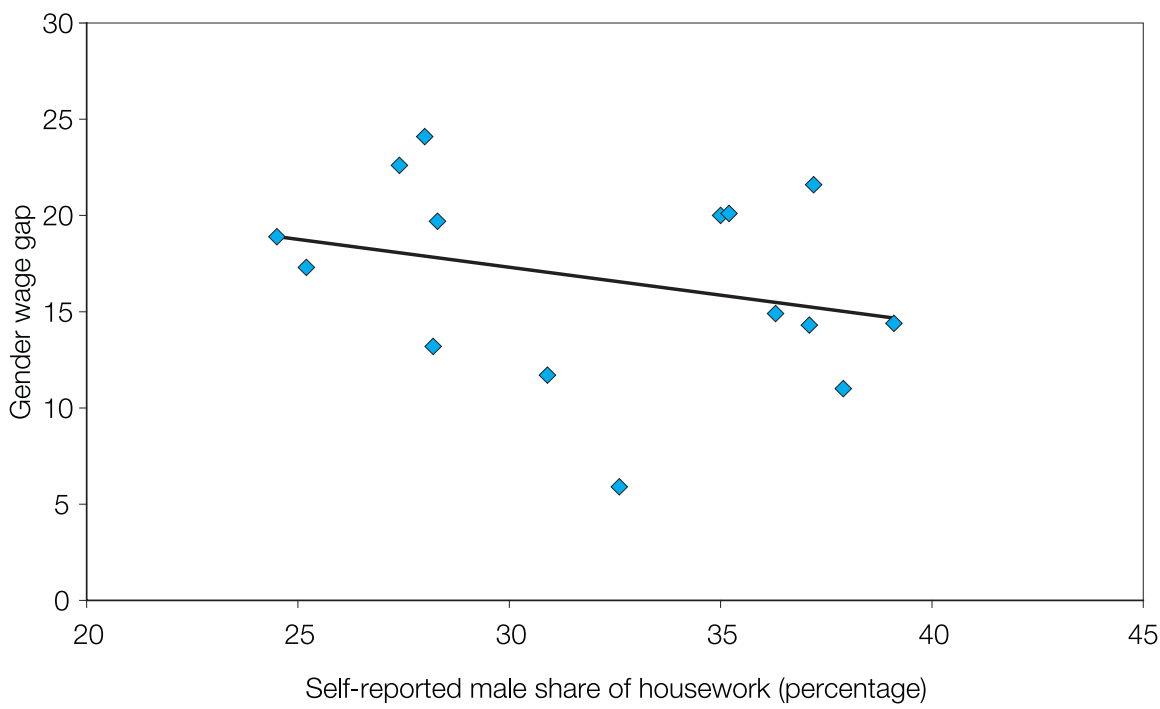

Note: An illustration of the correlation between the gender wage gap (measured as the difference between male and female median full-time earnings as a percentage of male median full-time earnings) and male housework hours in advanced economies (Australia, Denmark, Finland, France, Germany, Hungary, Ireland, New Zealand, Poland, Portugal, Spain, Sweden, Switzerland, United Kingdom, United States). The figure shows high male hours in housework to be correlated with smaller gender wage differentials.

Source: Data from Davis, Greenstein and Gerteisen Marks (2007) and OECD (2007). 
(2005) and Chichilnisky and Eisenberger (2005) also argue that there are specialization (learning by doing) effects but, in contrast to Becker (1985), they invoke a logistic production function, which changes from convexity to concavity through an inflection point. Chichilnisky and Eisenberger (2005) show that for the concave part of the production function, to which highly skilled societies belong, equal shares of effort and equal wages are efficient, whereas for the convex part of the production function, to which unskilled societies belong, efficiency requires specialization. Chichilnisky (2005) argues that missing contracts between the family and the workplace, and absence of private property rights to labour input within households, lead to an outcome with an unequal division of labour between husband and wife. Firms and families play the equivalent of a prisoner's dilemma game, and the outcome is a Pareto-inefficient gender wage gap. Another related paper is Albanesi and Olivetti (2007), who focus on labour market attachment in order to explain a persistent gender wage gap. The idea is that asymmetric information forces firms to offer labour contracts, which take incentive problems into account. Firms will offer different compensation to men and women if the firms expect men and women to differ systematically in labour allocation in the household.

As in this literature, we consider an economy in which men and women, who constitute couples (households), are ex-ante generically identical except for gender. ${ }^{6}$ Our model, however, departs in the way we perceive the functioning of households. While the previous literature generally assumes that household production can occur with input from only one spouse, we introduce complementarity and essentiality of labour in home production (using a Cobb-Douglas specification). Households cannot operate unless both spouses provide time inputs. This assumption is in accordance with time-use studies of advanced economies. These show that although men do less household work than women, they do not completely specialize in labour market activities (e.g. Freeman and Schettkat, 2005). Furthermore, strict essentiality seems justifiable for household activities which concern reproduction; and, more generally, one can argue that without mutual affection and attention, there will be no household production by either family member. We maintain the assumption of increasing returns to specialization of labour in the workplace, ${ }^{7}$ as in Becker (1985), which we refer

${ }^{6}$ Another strand of the literature explains the gender wage gap by an inherent source of difference between men and women, which causes women to earn lower wages. See, for example, Elul, Silva-Reus and Volij (2002) and Siow (1998).

${ }^{7}$ It can be argued that the gap in hourly wages between part-time and full-time jobs to some extent reflects differences in effectiveness between short and long hours. Such a gap has been reported repeatedly (e.g. Department of Labor, 2005). In 2004, a full-time worker in the United States earned about US $\$ 19$ per hour, whereas part-time workers earned only US $\$ 10$. A portion of the difference, however, may be accounted for by occupational differences. Hirsch (2000) finds that the part-time wage gap diminishes considerably by controlling for age, sex, skill level, and other variables. Also Bonke, Datta Gupta and Smith (2005) discuss how increasing hours in household production are correlated with wages. They find that household work has a negative effect on female wages. The same is not completely true for men: low-end male wages are positively correlated with household work. 
to as indivisibility effects. Indivisibility effects imply that the more labour a person puts in at home, the less productive she is at work. ${ }^{8}$

The introduction of complementarity in household production has two implications for our results. First, we find that there exist both an equilibrium in which spouses differ in their labour allocation, and an equilibrium in which all workers have identical labour allocations. A gender wage gap occurs when there are gender differences in labour allocation. In turn, gender differences in labour allocation occur if beliefs about wages are stereotyped. ${ }^{9}$ If beliefs are indeed stereotyped, the labour market dictates a wage rate for women and a wage rate for men. ${ }^{10}$ There is some empirical evidence supporting "more egalitarian division of labour at home in nations where there is a greater gender equity" (Davis, Greenstein and Gerteisen Marks, 2007, p. 1266). This means that in countries where cultural change at home is faster, wage differentials will shrink faster in the marketplace.

Another prediction of our model is that the wage gap is the widest for the highest-paying jobs. We thus provide a theoretical foundation for the empirical observation that the gender wage gap is wider in higher-paid occupations - a situation generally attributed to the so-called glass ceiling (see, for example, Albrecht, Björklund and Vroman, 2003; Arulampalam, Booth and Bryan, 2007; Meyersson Milgrom and Petersen, 2006).

Second, by use of numerical examples, we find that welfare in society is highest when spouses' labour allocations and wage rates are the same. How, then, can the apparent persistence of the gender wage gap in modern society be explained? We suggest that the self-fulfilling nature of traditional gender roles impedes their own effacement.

The remainder of this article is divided into five sections, as follows. In the first section, we develop a model in full generality by describing the representative husband-wife family, the representative firm, and the equilibrium. In the next section, we solve our model and present the results. The welfare aspects of equilibria are discussed in the third section, and policy implications, in the fourth. The final section provides some concluding remarks.

\section{The model}

The economy consists of two sectors, a formal sector and a home sector. Each sector is made up of a number of identical firms and families. The home sector produces household services and the formal sector produces a market commodity.

\footnotetext{
${ }^{8}$ Chichilnisky and Shachmurove (2006) examine the effect on wages of time used in household production. They find that time spent on household work explains 8 per cent of wage differences in the United States.

${ }^{9}$ By stereotyped, we mean conforming to traditional sex-role patterns.

10 We stress that this mechanism is conceptually different from discrimination since, in our model, the wage rates for men and women coincide when initial beliefs are unisex.
} 
The constant $\bar{N}$ denotes the number of families. Families consist of a husband and a wife, who are identified by an index $i \in\{1,2\}$.Family members are exante identical except for gender. They supply labour to the firm, $\left(l_{i}\right)$, and to the family, $\left(t_{i}\right)$, and have constant labour endowments, $\bar{T}$. We think of the labour endowment as the daily number of hours devoted to work activities (table 1); thus,

$$
l_{i}+t_{i}=\bar{T}
$$

with $l_{i}$ and $t_{i}$ henceforth expressed in number of hours as a share of total daily labour endowment. Family members do not derive utility from leisure and personal time.

\section{Families}

The representative family consumes the market commodity, $x$, and household services, $z$, which we think of as including activities such as food preparation, cleaning, shopping, dishwashing, transportation, household up-keeping, care for clothes, child and family care, do-it-yourself housework, gardening, and so forth. The market commodity is purchased from the market. The household service, on the other hand, is produced and consumed entirely within the home. ${ }^{12}$

We assume strict essentiality and complementarity in home production in the sense that neither spouse can produce without labour input from the other. Specifically, home production is given as:

$$
z=\left(t_{1} t_{2}\right)^{\frac{\beta}{2}},
$$

where, if $z>0$, then $t_{1}>0$ and $t_{2}>0$. Moreover, $0<\beta \leq 1$. We assume there are constant or decreasing returns to male and female labour input taken together. The literature shows no strong a priori on this point, ${ }^{13}$ but the constant returns formulation is often used for its convenience in empirical analysis (Apps and Rees, 1997; Aronsson, Daunfeldt and Wikström, 2001). Note that the factor shares of female and male labour input are taken to be identical. This reflects the idea that husband and wife are equally productive if they allocate their labour equally. Each family member has identical preferences and an equal weight in the family

11 We refer to any combination $\left(t_{i}, l_{i}\right)=\left(t_{i} ; \bar{T}-t_{i}\right)$ as the family member's labour (or time) allocation between the home sector and the firm sector.

12 One could argue that household services are to a certain extent available on a formal market. Time-use studies, however, show that families produce (at least part of) the service themselves (Bonke, Datta Gupta and Smith, 2005; Freeman and Schettkat, 2005; Short, 2000).

13 Becker (1985), Chichilnisky (2005), and Chichilnisky and Eisenberger (2005) do not assume complementarity in home production. Becker (1985) furthermore assumes increasing return to specialization, whereas Chichilnisky (2005) and Chichilnisky and Eisenberger (2005) assume a logistic production function. 
welfare function in conformity with a conventional unitary household model ${ }^{14}$ with household production. The family utility function, $\mathrm{u}$, is for convenience taken to be linearly additive:

$$
u(x, z)=a x+b z
$$

where $a>0$ and $b>0$ are parameters. For given hourly wage rates, $w_{1}$ and $w_{2}$, the family maximizes its utility

$$
\max _{t_{1}, t_{2}} u(x, z)
$$

subject to its budget, production, and labour constraints:

$$
\begin{gathered}
p_{x} x=w_{1} l_{1}+w_{2} l_{2}, \\
z=\left(t_{1} t_{2}\right)^{\frac{\beta}{2}}, \\
l_{\mathrm{i}}+t_{\mathrm{i}}=\bar{T}, \quad i \in\{1,2\},
\end{gathered}
$$

by efficiently allocating labour to home production and to earning market wages. The price, $p_{x}$, of the market commodity is our numeraire.

The household service is not traded, and therefore it has no market price. However, a price for the household service, $p_{z}$, can be defined as a shadow price at an optimum. Using the wage rate as the shadow price of labour input to home production, we can derive $p_{z}$ as the ratio $b / a$, since intra-household efficiency in the family consumption allocation requires that the marginal rate of substitution between the two goods equals their price ratio,

$$
\frac{\partial u / \partial x}{\partial u / \partial z}=\frac{p_{x}}{p_{z}}
$$

In a solution where $l_{i}>0$ and $t_{\mathrm{i}}>0$, an efficient allocation of labour endowments is reached when the marginal value product of labour in home production equals its opportunity cost (the hourly wage rate). Specifically, the first order

14 This aspect of our model could be made more general by using a collective household model (Chiappori, 1988), which allows household members to have different preferences and to have different weights in the family welfare function. 
conditions of the family utility maximization problem in such a solution can be expressed as:

$$
\begin{aligned}
& \frac{b}{a} \frac{\partial\left(t_{1} t_{2}\right)^{\frac{\beta}{2}}}{\partial t_{1}}=w_{1}, \\
& \frac{b}{a} \frac{\partial\left(t_{1} t_{2}\right)^{\frac{\beta}{2}}}{\partial t_{2}}=w_{2}
\end{aligned}
$$

and dividing (8) by (9), we obtain an expression for the gender wage ratio (or gap):

$$
\frac{w_{1}}{w_{2}}=\frac{t_{2}}{t_{1}}
$$

By (10), the wage ratio equals the inverse ratio of labour input into household production; if the wife earns relatively higher wage rates than her spouse, she allocates relatively less time to home production than he does, and vice versa. ${ }^{15}$ If family members earn the same wage rate, they allocate labour in the same manner.

The first order conditions, (8) and (9), are in general not satisfied in case of boundary solutions, i.e. when $l_{i}=0$ or $t_{i}=0$. Such situations occur if the marginal cost of the household service is different from its price for any allocation of labour.

\section{Firms}

The representative non-discriminating 16 firm operates in a competitive market and produces a market commodity using labour as input. It decides how many male and female workers to employ $\left(N_{1}\right.$ and $\left.N_{2}\right)$, taking the hours of labour supplied by each worker ${ }^{17}$ and the hourly wage rates as given. As firms and families are separate institutions that do not connect informationally, firms cannot control the labour supply of either spouse.

Workers produce output. Let $e$ denote the effectiveness of each unit of labour input at the firm. We assume that effectiveness is unrelated to gender type,

15 This prediction is tested by Albanesi and Olivetti (2007) on American data. They find a significant negative correlation between the husband-wife ratio of earnings and their home hours ratio.

16 Meyersson Milgrom, Petersen and Snarland (2001) find that, in Sweden, men and women doing the same work for an employer are paid the same salary. In academic labour markets, however, evidence of discrimination has consistently appeared (Blackaby, Booth and Frank, 2005).

17 This assumption may at first seem to contradict the conventional assumption that labour demand decreases as wages rise. This would be true if we did not distinguish between the number of workers and number of hours worked. Indeed, we postulate that workers and hours are not perfectly substitutable (see, for example, Cahuc and Zylberberg, 2004, for a discussion). 
but only a function of labour allocation. In particular, we assume that due to indivisibility of labour in the workplace, effectiveness (linearly) increases in hours per day in employment:

$$
e=e\left(l_{i}\right)=l_{i}
$$

so $\frac{\partial e\left(l_{i}\right)}{\partial l_{i}}>0$.

Indivisibility effects of labour in the workplace imply that one employee working $2 T$ hours produces more than two employees working $T$ hours each. Arguments in favour of this relationship include sunk costs, such as start-up costs. Moreover, if more workers are assigned to the same project, they may have to exchange information and update one another, which is likely to be costly in terms of productivity. The assumption also reflects the value to the firm of an employee's unconditional availability. The more time an employee spends on the job, the more likely it is that the employee will be able to respond immediately to emergencies and urgent requests. Arguments can furthermore be made in favour of learning-by-doing effects; the more time a worker spends producing, the more productive the worker becomes.

The firm's output per day, $q$, is the sum of the output produced by each employee per day given as

$$
q=A\left[e\left(l_{1}\right) l_{1} N_{1}+e\left(l_{2}\right) l_{2} N_{2}\right]
$$

where $A$ is a positive productivity term, and

$$
\frac{\partial q}{\partial N_{i}}=A e\left(l_{i}\right) l_{i}
$$

is the marginal productivity of a worker $i$, which depends on the number of hours the worker puts into production. As $l_{i}$ is taken as given by the firm, which is an assumption of competitive firms, the firm has constant returns to scale in employment. An implication of (11) in (12) is that longer hours worked at the firm lead to higher marginal productivity of both labour and workers. Importantly, this effect is not internalized by households, as the households in their utility maximization problem, (3)-(7), take wages as given.

The firm decides how many workers to recruit in order to maximize its profits, $\pi$, which are the firm's revenues minus its costs. As the price of the market commodity is the numeraire, the profit maximization problem is

$$
\max _{N_{1}, N_{2}} \pi=\left\{A\left[e\left(l_{1}\right) l_{1} N_{1}+e\left(l_{2}\right) l_{2} N_{2}\right]-w_{1} l_{1} N_{1}-w_{2} l_{2} N_{2}\right\} .
$$

Assuming a competitive market, one takes the prices of $w_{1}, w_{2}, l_{1}$ and $l_{2}$ as given, and the firm employs workers until their marginal daily productivity, $A e\left(l_{i}\right) l_{i}$, equalizes their marginal daily costs, $w_{1} l_{i}$. Hence, 


$$
\begin{aligned}
& \frac{\partial \pi}{\partial N_{1}}=A e\left(l_{1}\right) l_{1}-w_{1} l_{1}=0 \Leftrightarrow A e\left(l_{1}\right)-w_{1}=0 \\
& \frac{\partial \pi}{\partial N_{2}}=A e\left(l_{2}\right) l_{2}-w_{2} l_{2}=0 \Leftrightarrow A e\left(l_{2}\right)-w_{2}=0 .
\end{aligned}
$$

Since labour, $l_{1}$ and $l_{2}$, is measured in hours, the solution to the firm's problem depends on the relationship between hourly wages and the effectiveness of an hour of labour at the firm adjusted by the productivity term $A$. In the following, we refer to $A e\left(l_{\mathrm{i}}\right)$ as the average productivity of labour per hour, $i=\{1,2\}$. We have three different situations describing the firm's employment demand:

$$
N_{i}=\left\{\begin{array}{c}
\infty \text { if } \operatorname{Ae}\left(l_{i}\right)>w_{i}, \\
{\left[0, \infty\left[\text { if } A e\left(l_{i}\right)=w_{i},\right.\right.} \\
0 \text { if } \operatorname{Ae}\left(l_{i}\right)<w_{i} .
\end{array}\right.
$$

If $A e\left(l_{i}\right)>w_{i}$ the firm would want to hire an infinite number of type $i$ workers; if $A e\left(l_{\mathrm{i}}\right)<w_{i}$ the firm would not want to hire any type $i$ workers; and if $A e\left(l_{i}\right)=w_{i}$ the firm is indifferent about the number of type $i$ workers.

\section{Equilibrium}

The conditions for existence of a competitive equilibrium in the economy involve: (i) the labour market, (ii) the market commodity, and (iii) the household service.

There are two types of equilibria. An interior equilibrium, in which the production levels of both $x$ and $z$ are strictly positive, ${ }^{18}$ and a specialized equilibrium, in which only one sector is producing.

An interior equilibrium involves a positive price vector, $\left(w_{1}, w_{2}\right)$, at which markets for male and female labour, as well as the market commodity and the household service, clear; and for which the marginal conditions for an optimum given by the firm's and the family's first order conditions are satisfied.

There is a market clearing condition for each of the two goods. For every family, maximization of utility, (3)-(7), yields a labour allocation which satisfies

$$
p_{z} z=\frac{b}{a}\left(t_{1} t_{2}\right)^{\frac{\beta}{2}},
$$

${ }^{18}$ From the complementarity of male and female labour inputs in home production, it follows that when home production is operative, then $t_{1}>0$ and $t_{2}>0$. Moreover, as we prove in proposition 2 below, an equilibrium where only one spouse spends all of her/his time in home production does not exist. But if the household service could be produced separately by each spouse, at least one individual would completely specialize in this sector. This result resembles Theorem 2.3 in Becker (1991, p. 34). 
so that household services consumed equal household services produced. Also, the market-commodity production must equal the market-commodity demand. As the firm's production technology is linear-homogenous in employment, we can normalize the number of firms to unity. In this case,

$$
q=\bar{N} x
$$

holds, where

$$
q=A\left[e\left(l_{1}\right) l_{1} N_{1}+e\left(l_{2}\right) l_{2} N_{2}\right] \text { and } \bar{N} x=\bar{N}\left(w_{1} l_{1}+w_{2} l_{2}\right) .
$$

Finally, the labour market clearing conditions are as follows. If there is a solution with a finite market commodity production, then from (16) it follows that

$$
A e\left(l_{i}\right)=w_{i}
$$

holds. ${ }^{19}$ Hence, (20) is a necessary condition for an interior competitive equilibrium. Together with the constant returns assumption on $N_{i}$ (not on $l_{i}$ ), (20) implies that the competitive firm is indifferent about the number of workers it employs. In equilibrium, the number of female and male workers, $N_{1}$ and $N_{2}$, equals the number of families $\bar{N}$; i.e. $N_{1}=N_{2}=\bar{N}$.

Substituting (11) in (20) gives the following employment clearing conditions:

$$
A l_{1}=w_{1}
$$

and

$$
A l_{2}=w_{2}
$$

In addition, the productivity of an hour of labour equals the hourly wage. In the interior equilibrium, female and male labour supply equals female and male labour demand when (8) equals (21) and (9) equals (22). Using $l_{i}=\bar{T}-t_{i}$ we can derive two equations in $t_{1}$ and $t_{2}$ :

$$
\begin{aligned}
& A\left(\bar{T}-t_{1}\right)=\frac{b}{a} \frac{\beta}{2} t_{1}^{\frac{\beta-2}{2}} t_{2}^{\frac{\beta}{2}}, \\
& A\left(\bar{T}-t_{2}\right)=\frac{b}{a} \frac{\beta}{2} t_{1}^{\frac{\beta}{2}} t_{2}^{\frac{\beta-2}{2}} .
\end{aligned}
$$

Equations (23) and (24) state that, in an equilibrium, the average productivity of one hour of labour in the workplace has to equal the marginal value product of labour in home production.

${ }^{19}$ If $A e\left(l_{i}\right)<w_{i}$ holds, production of the consumption good is zero, and if $A e\left(l_{i}\right)>w_{i}$ holds, the firm earns positive profits. 
We can now characterize an interior equilibrium as any combination of $t_{1}$ and $t_{2}$ which solves (23) and (24). Such a combination clears markets for male and female labour, and supports a price vector, $\left(w_{1}, w_{2}\right)$, for which, also, the market for $x$ clears, and firms earn zero profits.

\section{Results}

In solving the model, it is useful to define a labour allocation for which $t_{1}=t_{2}$ as symmetric, and one for which $t_{1} \neq t_{2}$ as asymmetric. Both cases can occur, but by (21) and (22), only an asymmetric situation leads to what is known as a gender wage gap. Specifically, we have

LEMMA 1 (symmetric equilibrium)

If

$$
0<\beta<1 \text { and } \frac{b}{a} \frac{\beta}{2 A}<\left(\frac{\bar{T}}{2-\beta}\right)^{2-\beta} \times(1-\beta)^{1-\beta},
$$

then there exist two interior symmetric equilibria.

If

$$
\beta=1 \text { and } \frac{b}{a} \frac{1}{2 A}<\bar{T},
$$

then there exists one interior symmetric equilibrium (see Appendix for proof).

Similarly, we analyse the asymmetric equilibrium.

LEMMA 2 (asymmetric equilibrium)

If

$$
\frac{b}{a} \frac{\beta}{2 A}<\left(\frac{\bar{T}}{2}\right)^{2-\beta}
$$

then there exist two interior asymmetric equilibria (see Appendix for proof).

It follows from the proof of lemma 2, that the two equilibria are distinguished purely by which spouse supplies most time input into household production. If in one equilibrium, one spouse supplies the highest numbers of hours, $t^{h}$, to the household, then the other spouse supplies $t^{l}=\bar{T}-t^{h}$. The situation is reversed in the other equilibrium, i.e. household members may allocate labour according to traditional gender roles, where the wife supplies the most time input to the household production, or inversely. 
PROPOSITION 1 (multiple interior equilibria). If an interior asymmetric equilibrium is supported by a positive price vector

$$
\left(w_{1}, w_{2}\right)
$$

there exists another price vector

$$
\left(\widetilde{w}_{1}, \widetilde{w}_{2}\right) \neq\left(w_{1}, w_{2}\right)
$$

which supports an interior symmetric equilibrium (see Appendix for proof).

By proposition 1, we establish that for some sub-interval of the values for the productivity term, $A$, and the weights in the utility function, $a$ and $b$, the model has multiple interior equilibria which result either in gender-similarities or in gender-differences in labour allocation.

This result is important in the sense that it mirrors the self-fulfilling nature of expectations about gender roles. On the one hand, the family's efficient response to traditional beliefs about earnings is actually to allocate labour stereotypically. On the other hand, the family's efficient response to unisex beliefs is to allocate labour identically. Proposition 1 thus suggests that the persistence of the gender wage gap relates to the persistence of perceptions of gender roles. We discuss this issue in further detail in the final section, but it must first be pointed out that the model has interesting comparative statics for the asymmetric equilibrium.

Proposition 2. Assume the economy is in an asymmetric equilibrium. A higher productivity level $A$ is associated with a larger gender wage gap (see Appendix for proof).

For a given initial asymmetric labour allocation, we consider a situation where $A$ increases and, consequently, so does labour productivity in the firm. The person with the lower $t$ (the most labour allocated to the firm) experiences the highest increase in hourly wage as the average productivity of an hour of labour increases in $A$ at the rate $(\bar{T}-t)$.

As is clear from (10), the family's efficient labour-allocation response to such a change in the relative hourly wage rates is that the person who works most at the firm allocates more labour to the firm, and the person who works most at the home allocates more labour to the home. The person who works most in the home therefore ends up earning a lower wage than in the original equilibrium. In this way, increases in $A$ magnify any existing differences in productivity.

Assuming that couples predominantly exist within similar occupations, ${ }^{20}$ proposition 2 predicts that the gender wage gap is larger within families that work in sectors with higher wage rates.

20 Blossfeld and Timm (2003) present some empirical evidence for educational homogamy, i.e. individuals marry individuals with similar characteristics such as occupation, education and religion. 
Figure 2. Gender differences in earnings across occupations in the United States

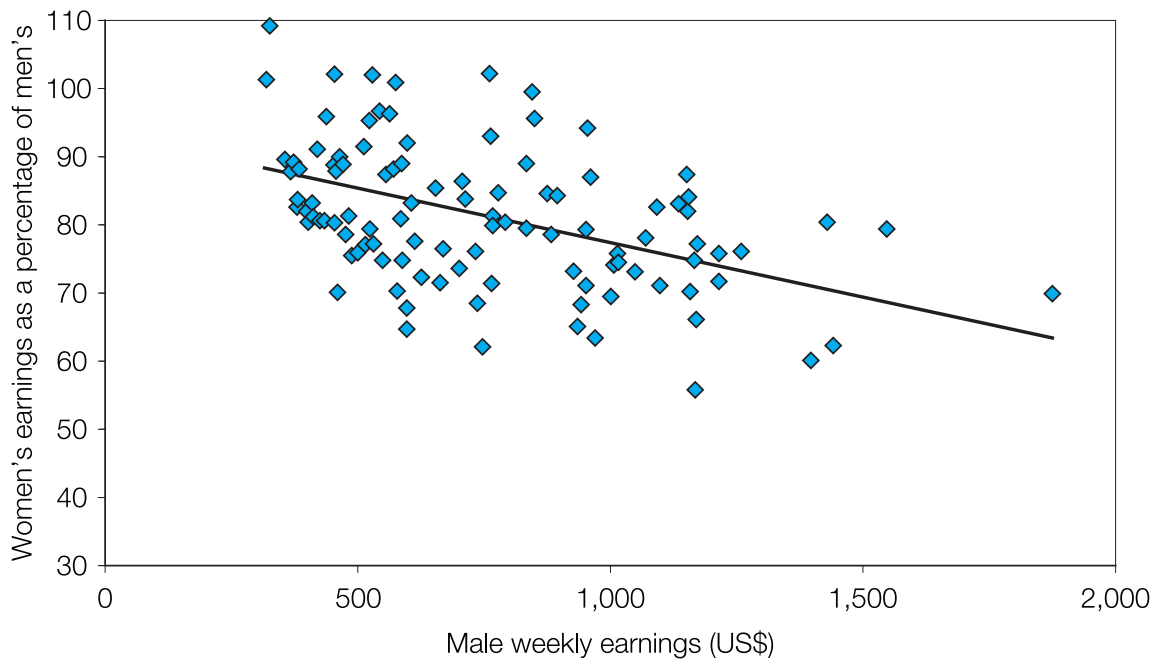

Note: The figure shows that higher male earnings within an occupation are correlated with a larger gender wage gap, i.e. lower women's earnings relative to those of men.

Source: Data from United States Department of Labor, 2005, table 2.

Figure 2 is a scatter plot of female/male earnings ratio against male earnings for different occupations. Each dot in the scatter plot represents an occupation (e.g. civil engineers, lawyers, photographers, etc). If couples exist within similar occupations, then figure 2 confirms proposition 2: the corresponding regression ${ }^{21}$ reveals a statistically significant negative relationship between male median weekly earnings and the gender wage ratio. This pattern is also referred to as the glass ceiling; the higher paid the occupation, the larger the salary discrimination against women. The literature which looks into how the gender wage gap varies across the wage distribution is just starting to emerge. Current empirical evidence, however, seems to support our result. Arulampalam, Booth and Bryan (2007) analyse the wage gap distribution in 11 European countries. ${ }^{22}$ They find evidence of a widening of the gender wage gap at the top of the wage distribution. Albrecht, Björklund and Vroman (2003) find similar results for Sweden.

Another interpretation of the glass ceiling is that, within firms, there is a rank or level beyond which women are rarely promoted. Meyersson Milgrom and Petersen (2006) find evidence of this situation in Sweden.

21 The intercept estimate is 92.99 (38.66) and the slope estimate is $-0.02(-5.26)$, the numbers in parentheses being the $t$-statistics. The fraction of the variation in the wage gap explained by the regression is above 20 per cent $\left(R^{2}\right.$ is 0.21$)$.

22 Austria, Belgium, Denmark, Finland, France, Germany, Ireland, Italy, the Netherlands, Spain and the United Kingdom. 


\section{Welfare analysis by numerical examples}

This section analyses the welfare properties of the gender wage gap in the context of the present model. Let overall welfare in society, $V$, be given by the sum of household utilities and firm profits

$$
V=\bar{N} u(x, z)+\pi=\bar{N} u(x, z),
$$

where the last equality follows from firms earning zero profits in equilibrium. In the following, we can thus analyse utility levels of the representative family. In order to be able to compare welfare levels across different types of equilibria, we proceed by use of numerical examples. Table 2 reports simulated equilibria. The last simulation in each panel of the table offers a parameterization which, in the asymmetric simulation, gives a gender wage ratio corresponding to the range of typical gender wage-ratio estimates (see OECD, 2002, chapter 2).

Table 2 presents different combinations of the parameters of the model. Labour allocation in the symmetric situation is indicated by $t^{h}$ and $t^{l}$, where $t^{h}$ denotes the situation in which the spouses allocate the most labour to home production, and $t^{l}$, the one in which they allocate the least labour to home production. Also indicated for both equilibria are the welfare levels of the representative family, given production of the market commodity, $x$, and of the household service, $z$.

The family consumes different ratios of the household service and the market commodity across equilibria. Comparing welfare levels, however, we find that utility is highest for the equilibrium in which spouses allocate most labour to the workplace, i.e. in $t=t^{l}$ (column " $l$ " in table 2). This is mainly due to the negative spillover effect of home production onto labour productivity at the firm. The extra production of the market commodity more than compensates for the decline in home production.

In the asymmetric equilibria, we report the equilibria in which women spend most time in the household. ${ }^{23}$ Therefore, the gender wage gap, $\rho$, is the wife-husband wage ratio. As predicted in proposition 2, a higher $A$ increases the gender wage gap, i.e. decreases the wife-husband wage ratio (in table 2 , for $\beta=0.6$, the $\rho$-values increase from 0 to 0.01 and then to 0.03 ).

To examine the welfare properties of the gender wage gap, we compare the asymmetric equilibrium with the symmetric equilibria. We find that production of the market commodity is higher everywhere in the symmetric equilibrium in which $t=t^{l}$ than in the asymmetric equilibrium. At the same time, however, production of the household service is higher in the asymmetric equilibrium than in this symmetric equilibrium. Yet the extra production for the market makes up for the loss of household services and welfare is higher in the symmetric equilibrium. For the model presented in this article, the simulations thus suggest that a gender wage gap is Pareto inferior in that welfare in the symmetric equilibrium (with the

23 The welfare results apply equally to the reverse situation, in which men spend most time in the household. 
Table 2. Simulated equilibria and welfare outcomes, $\bar{T}=10$

\begin{tabular}{|c|c|c|c|c|c|c|c|c|c|c|}
\hline \multirow{3}{*}{$\frac{b}{A a}$} & \multirow[t]{3}{*}{$\beta$} & \multicolumn{5}{|c|}{ Symmetric } & \multicolumn{4}{|c|}{ Asymmetric } \\
\hline & & \multicolumn{2}{|l|}{$t^{a}$} & \multicolumn{2}{|c|}{$\begin{array}{l}\text { Value of welfare } \\
\text { function } u(x, z)\end{array}$} & \multirow[t]{2}{*}{$\rho$} & \multirow[t]{2}{*}{$t_{1} \mathrm{~d}$} & \multirow[t]{2}{*}{$t_{2}$} & \multirow[t]{2}{*}{$\begin{array}{l}\text { Value of welfare } \\
\text { function } u(x, z)\end{array}$} & \multirow[t]{2}{*}{$\rho$} \\
\hline & & $t^{\prime}$ & $t^{h}$ & lb & $h^{c}$ & & & & & \\
\hline 10 & 0.3 & 0.07 & 9.69 & 201.71 & 19.96 & 1 & 9.84 & 0.16 & 107.56 & 0.00 \\
\hline 10 & 0.6 & 0.05 & 8.74 & 199.66 & 39.90 & 1 & 9.49 & 0.51 & 106.37 & 0.00 \\
\hline 10 & 0.9 & 0.00 & 6.25 & 200.00 & 80.16 & 1 & 8.10 & 1.90 & 103.43 & 0.06 \\
\hline 15 & 0.3 & 0.12 & 9.54 & 203.17 & 29.93 & 1 & 9.73 & 0.27 & 112.08 & 0.00 \\
\hline 15 & 0.6 & 0.14 & 8.05 & 199.05 & 60.03 & 1 & 9.05 & 0.95 & 111.41 & 0.01 \\
\hline 15 & 0.9 & 0.02 & 4.15 & 299.65 & 122.44 & 1 & - & - & - & - \\
\hline 20 & 0.3 & 0.18 & 9.37 & 204.82 & 39.93 & 1 & 9.62 & 0.38 & 116.98 & 0.00 \\
\hline 20 & 0.6 & 0.30 & 7.26 & 197.89 & 80.72 & 1 & 8.47 & 1.53 & 117.21 & 0.03 \\
\hline 20 & 0.9 & 0.90 & 1.00 & 183.81 & 182.00 & 1 & - & - & - & - \\
\hline 13 & 0.9 & 0.01 & 5.02 & 199.81 & 105.14 & 1 & 5.42 & 4.58 & 105.51 & 0.71 \\
\hline
\end{tabular}

a Across the symmetric equilibria, $t^{\prime}$ and $t^{h}$ are the "low" and "high" equilibrium values $\left(t^{\prime}<t^{h}\right)$ of labour spent in home production. b The label "l" indicates the welfare values which correspond to $t^{l}$ (lowest allocation of labour to home production). c The label " $h$ " indicates the welfare values which correspond to $t^{h}$ (highest allocation of labour to home production). d In the asymmetric equilibrium, $t_{1}$ and $t_{2}$ denote the labour allocated to home production by the woman and the man respectively.

least labour used in home production, i.e. $t=t^{l}$ ) is higher everywhere than welfare in the asymmetric equilibrium.

\section{Discussion}

Although the model does not provide a-priori insight as to which specific equilibrium outcome will emerge from among the possibilities of interior equilibria, a key prediction is that if families believe that wages are gender-stereotyped, the economy will experience a gender wage gap, with women earning less than men. In this sense, the gender wage gap is explained as a self-fulfilling prophecy.

A natural way for today's families to decide on labour allocation would be to use information on "yesterday's" wages. If, for what could be historical and cultural reasons, women used to be less educated than men and to participate less in the labour force, it would have been rational that women historically earned less than men. Yet, even though the premises which determined this historical labour market outcome have changed - in that today's women and men share the same starting point for becoming equally productive in both the home and the workplace - current beliefs about earnings may be "historically biased" in favour of stereotypes. This reasoning leads us to argue that persistence of the gender wage gap in developed societies can possibly be explained by a self-fulfilling "history bias" in beliefs.

An implication of this result is that family reality and family beliefs about earnings have to change simultaneously for the economy to move from the stereotyped asymmetric equilibrium to a unisex symmetric equilibrium. Effective 
policies to that end therefore have to be policies that can change the norms of society. ${ }^{24}$ Without such policies the gender wage gap is likely to persist as a rational reaction to stereotyped family beliefs about gender roles, even when there is no actual gender discrimination or other initial differences between women and men.

In conformity with this analysis, Hakim (2004) finds that the majority of couples aim for traditional gender roles within British families. Hakim argues that one explanation is that women regard themselves as secondary earners, and that employment does not provide them with their central identity. ${ }^{25}$ Davis, Greenstein and Gerteisen Marks (2007) find in their cross-sectional empirical work that higher gender equity in society (measured by an index) is related to higher equity in the division of labour at home.

Culture and societal norms partly originate from within families. Changing these structures is indeed very difficult, and policy-makers cannot resolve this problem alone. It is possible, however, to think of new institutions that while private can be ratified or acknowledged publicly, so as to deal with this problem. For example, the state can give widespread recognition and legal acceptance to private contracts or institutions such as "prenuptial" agreements (which are private contracts, beyond policy-makers' control, but which can be regulated publicly by imposing fines for discrimination against women in the household in breach of the agreement). Such prenuptial agreements would help to resolve the firm's uncertainty about the type of marriage that will develop after the fact of marriage and children. A prenuptial agreement sanctioned by the state, could indeed help to resolve the problem we have identified.

Another explanation of why families do not change their traditional genderrole perceptions could be that both men and women view equity as a relevant concept in the workplace, but that neither view the home as a workplace. Roughly speaking, if housework is a "woman's labour of love" equity does not come into question. Moreover, men and women may define certain jobs as feminine and others as masculine. A woman is less of a woman if she does not keep the house, and the man is less of a man if he does. Since the majority of households have an unequal division of labour, if men compare themselves to other men, and women to other women, both women and men are likely to perceive traditional gender roles as normal and desirable (Hakim, 2003; Valian, 1999).

There is also a large body of empirical literature which analyses the gender wage gap. Explanations include the so-called family gap: women who marry and have children experience a wider wage gap than unmarried women with no children (Ginther, 2004; Waldfogel, 1998; Winder, 2004), higher levels of occupational segregation, i.e. men and women are allocated gender-specifically to occupations that differ in the wages they pay (Meyersson Milgrom, Petersen and Snarland, 2001), and more self-selection of women into sectors with relatively

24 Chichilnisky (2005) argues that even if the economy is in the equal-wage equilibrium, further policy measures are needed to prevent a prisoner's dilemma game between the family and the firm from evolving and leading to a stereotyped equilibrium outcome.

25 She also finds that families without children have a traditional division of labour. 
lower wage growth (Rosholm and Smith, 1996). Other explanations suggest that family-friendly policies may have adverse effects on female wages (Datta Gupta, Oaxaca and Smith, 2006). Finally, Blackaby, Booth and Frank (2005) suggest that discrimination causes women to be underpaid. Still, however, a large fraction of the gender wage gap seems to remain unaccounted for (Blau and Kahn, 2006).

\section{Concluding remarks}

Inspired by Becker (1985) and Chichilnisky (2005), this article has investigated the gender wage gap. Like these models, our model does not build on genetic differences between the sexes. In Becker (1985), spouses gain from a division of labour between employment and household work: one specializes in employment and the other specializes in home-making. Such a division raises the productivity of both persons in both sectors and a gender wage gap is Pareto efficient. Chichilnisky (2005) uses a logistic production function specification in both sectors, which changes from convexity to concavity through an inflection point. Within this framework, Chichilnisky (2005) shows that Becker's Pareto efficiency result only holds for economies that are in the convex region, i.e. economies with a low-skilled labour force.

We have shown that changing the properties of household production, so that it invokes complementarity of spousal labour in home production, while maintaining Becker's specialization gains of labour input in the workplace, may lead to multiplicity of equilibria in which families' beliefs about the gender wage gap are self-fulfilling. If family members believe that women earn less than men, ex post, intra-household labour allocation justifies such beliefs. We therefore argue that women's past records on the labour market may have severe implications for labour market outcomes today, which are not easily overcome. Indeed, our welfare analysis revealed potential welfare gains to closing the gender wage gap. In this way, we have shown that the Pareto efficiency result in Chichilnisky (2005) also holds in a model where home production follows a Cobb-Douglas specification, even when there are specialization gains in the market employment sector.

One limitation of our welfare analysis is the restrictive assumption that household goods and market commodities are perfect substitutes. In reality, households may have decreasing marginal utilities in both goods. This may change the Pareto efficiency result, and further research could address this issue.

\section{References}

Albanesi, Stefania; Olivetti, Claudia. 2007. Home production, market production and the gender wage gap: Incentives and expectations. Department of Economics Discussion Paper No. 0607-10. New York, NY, Columbia University.

Albrecht, James; Björklund, Anders; Vroman, Susan. 2003. "Is there a glass ceiling in Sweden?", in Journal of Labor Economics, Vol. 21, No. 1 (Jan.), pp. 145-177. 
Aronsson, Thomas; Daunfeldt, Sven-Olov; Wikström, Magnus. 2001. "Estimating intrahousehold allocation in a collective model with household production", in Journal of Population Economics, Vol. 14, No. 4, pp. 569-584.

Apps, Patricia F.; Rees, Ray. 1997. "Collective labor supply and household production", in Journal of Political Economy, Vol. 105, No. 1, pp. 178-190.

Arulampalam, Wiji; Booth, Alison L.; Bryan, Mark L. 2007. "Is there a glass ceiling over Europe? Exploring the gender pay gap across the wage distribution", in Industrial and Labor Relations Review, Vol. 60, No. 2 (Jan.), pp.163-186.

Becker, Gary S. 1985. "Human capital, effort, and the sexual division of labor", in Journal of Labor Economics, Vol. 3, No. 1, pp. 33-58.

-. 1991. A treatise on the family. Cambridge, MA, Harvard University Press.

Blackaby, David; Booth, Alison L.; Frank, Jeff. 2005. "Outside offers and the gender pay gap: Empirical evidence from the UK academic labour market", in Economic Journal, Vol. 115, No. 501, pp. F81-F107.

Blau, Francine D.; Kahn, Lawrence M. 2006. "The U.S. gender pay gap in the 1990s: Slowing convergence", in Industrial and Labor Relations Review, Vol. 60, No. 1, pp. 45-66.

-; -. 2000. "Gender differences in pay", in Journal of Economic Perspectives, Vol. 14, No. 4, pp. 75-99.

Blossfeld, Hans-Peter; Timm, Andreas (eds). 2003. Who marries whom? Educational systems as marriage markets in modern societies. Dordrecht, Kluwer Academic Publishers.

Bonke, Jens; Datta Gupta, Nabanita; Smith, Nina. 2005. "The timing and flexibility of housework and men and women's wages", in Daniel S. Hamermesh and Gerard A. Pfann (eds): The economics of time use. Contributions to Economic Analysis Series. Amsterdam, Elsevier, pp. 43-77.

Cahuc, Pierre; Zylberberg, André. 2004. Labor economics. Cambridge, MA, MIT Press.

Chiappori, Pierre-André. 1988. "Introducing household production in collective models of labor supply", in Journal of Political Economy, Vol. 105, No. 1, pp. 191-209.

Chichilnisky, Graciela. 2005. "The gender gap II", in Francesca Bettio and Giovanni Forconi (eds): XVIII workshop: Gender and economics. Lecture notes and papers. Siena, International School of Economic Research, pp. 1-17. (Forthcoming in Review of Development Economics.)

-; Eisenberger, P. 2005. Science and the family. Department of Economics Discussion Paper. New York, NY, Columbia University.

-; Shachmurove, Yochanan. 2006. An empirical analysis of the gender gap. Department of Economics Discussion Paper. New York, NY, Columbia University and University of Pennsylvania.

Coltrane, Scott. 2000. "Research on household labor: Modelling and measuring the social embeddedness of routine family work", in Journal of Marriage and Family, Vol. 62, No. 4,pp. 1208-1233.

Datta Gupta, Nabanita; Oaxaca, Ronald L.; Smith, Nina. 2006. "Swimming upstream, floating downstream: Comparing women's relative wage progress in the United States and Denmark", in Industrial and Labor Relations Review, Vol. 59, No. 2 (Jan.), pp. 243-266.

Davis, Shannon N.; Greenstein, Theodore N.; Gerteisen Marks, Jennifer P. 2007. "Effects of union type on division of household labor: Do cohabiting men really perform more housework?", in Journal of Family Issues, Vol. 28, No. 9, pp. 1246-1272.

Department of Labor. 2005. Highlights of women's earnings in 2004. Report 987. Washington, DC, United States Bureau of Labor Statistics.

Edin, Per-Anders; Richardson, Katarina. 2002. "Swimming with the tide: Solidary wage policy and the gender earnings gap", in Scandinavian Journal of Economics, Vol. 104, No. 1, pp. 49-67.

Elul, Ronel; Silva-Reus, José; Volij, Oscar. 2002. "Will you marry me? A perspective on the gender gap", in Journal of Economic Behavior and Organization, Vol. 49, No. 4, pp. 549-572. 
Freeman, Catherine E. 2004. Trends in educational equity of girls and women: 2004. NCES 2005-016. US Department of Education, NCES. Washington, DC, US Government Printing Office.

Freeman, Richard B.; Schettkat, Ronald. 2005. "Marketization of household production and the EU-US gap in work", in Economic Policy, Vol. 20, No. 41 (Jan.), pp. 7-50.

Fullerton, Howard N. 1999. "Labor force participation: 75 years of change, 1950-98 and 1998-2025", in Monthly Labor Review, Vol. 122, No. 12 (Dec.), pp. 3-12.

Ginther, Donna K. 2004. "Why women earn less: Economic explanations for the gender salary gap in science", in Awis Magazine, Vol. 33, No. 1, pp. 6-10.

Hakim, Catherine. 2004. Key issues in women's work: Female diversity and the polarisation of women's employment. Second edition. London, GlassHouse Press.

-.2003. Models of the family in modern societies: Ideals and realities. Aldershot, Ashgate.

Hirsch, Barry. 2000. The relative compensation of part-time and full-time workers. Washington, DC, Employment Policies Institute.

Meyersson Milgrom, Eva M.; Petersen, Trond. 2006. "The glass ceiling in the United States and Sweden: Lessons from the family-friendly corner of the world, 1970-1990", in Francine D. Blau, Mary C. Brinton and David B. Grusky (eds): The declining significance of gender? New York, NY, Russell Sage Foundation, pp. 156-211.

-; -; Snarland, Vemund. 2001. "Equal pay for equal work? Evidence from Sweden and a comparison with Norway and the US", in Scandinavian Journal of Economics, Vol. 103, No. 4 (Dec.), pp. 559-583.

OECD. 2007. LMF5: Gender pay gaps for full-time workers and earnings differentials by educational attainments. OECD Family Database, OECD - Social Policy Division Directorate of Employment, Labour and Social Affairs. Paris.

-.2002. Employment Outlook. Paris.

Rosholm, Michael; Smith, Nina. 1996. "The Danish gender wage gap in the 1980s: A panel data study", in Oxford Economic Papers, Vol. 48, No. 2 (Apr.), pp. 254-279.

Short, Sandra. 2000. Time use data in the household satellite account-October 2000. London, Economic Assessment and Strategy Division, Office for National Statistics.

Siow, Aloysius. 1998. "Differential fecundity, markets, and gender roles", in Journal of Political Economy, Vol. 106, No. 2 (Apr.), pp. 334-354.

Valian, Virginia. 1999. Why so slow? The advancement of women. Cambridge, MA, MIT Press.

Waldfogel, Jane. 1998. "The family gap for young women in the United States and Britain: Can maternity leave make a difference?", in Journal of Labor Economics, Vol. 16, No. 3, pp. 505-545.

Winder, Katie L. 2004. Reconsidering the motherhood wage penalty. Mimeo. Baltimore, MD, Johns Hopkins University. 


\section{A. Appendix}

\section{A.1 Proof of Lemma 1}

When $t_{1}=t_{2} \equiv t$, equation (23) and (24) collapse into

$$
(\bar{T}-t) t^{1-\beta}=\frac{b}{A a} \frac{\beta}{2} \text {. }
$$

In general, a solution to (26) exists when the right-hand side, which is parametrically given, is smaller than, or equal to, the maximum value of the left-hand side.

When $\beta<1$, the left-hand side is an inversely "U-shaped" polynomial with a unique maximum that is positively skewed. The maximum is found by first differentiating the left-hand side with respect to $t$, then setting this expression equal to zero, and finally isolate for $t$ :

$$
\frac{\partial(\bar{T}-t) t^{1-\beta}}{\partial t}=0 \Rightarrow t^{-\beta}[\bar{T}-2 t+(t-\bar{T}) \beta]=0 \Leftrightarrow \bar{T}\left(\frac{1-\beta}{2-\beta}\right)=t .
$$

Substituting this expression back into (26) determines the maximum value of the lefthand side as of this equation a function of $\beta$;

$$
\arg \max _{t}(\bar{T}-t) t^{1-\beta}=\left(\frac{\bar{T}}{2-\beta}\right)^{2-\beta}(1-\beta)^{1-\beta} .
$$

Hence, in an interior equilibrium

$$
\frac{b}{A a} \frac{\beta}{2} \leq\left(\frac{\bar{T}}{2-\beta}\right)^{2-\beta}(1-\beta)^{1-\beta}
$$

must be satisfied. When the equation holds with equality, there is exactly one solution, otherwise there are two solutions.

When $\beta=1$ the left-hand side of (26) is linear and equal to $(\bar{T}-t)$. Hence, the maximum is given when $t=0$, so

$$
\arg \max _{t}(\bar{T}-t)=\bar{T}
$$

For an interior equilibrium to exist,

$$
\frac{b}{a} \frac{1}{2 A}<\bar{T}
$$

\section{A.2 Proof of Lemma 2}

Dividing (23) and (24) means

$$
\frac{\bar{T}-t_{1}}{\bar{T}-t_{2}}=\frac{t_{2}}{t_{1}}
$$


must hold. Rewriting this expression yields

$$
\begin{aligned}
& \bar{T} t_{1}-t_{1}^{2}=\bar{T} t_{2}-t_{2}^{2} \Leftrightarrow \bar{T}\left(t_{1}-t_{2}\right)=t_{1}^{2}-t_{2}^{2} \Leftrightarrow \bar{T}\left(t_{1}-t_{2}\right) \\
& =\left(t_{1}+t_{2}\right)\left(t_{1}-t_{2}\right) \Rightarrow\left(t_{1}+t_{2}\right)=\bar{T}
\end{aligned}
$$

for $t_{1} \neq t_{2}$. Substituting $t_{1}=\bar{T}-t_{2}$ back into either (23) or (24), rearrange and solve for $t_{2}$ gives

$$
\left(\bar{T}-t_{2}\right) t_{2}=\left(\frac{b}{A a} \frac{\beta}{2}\right)^{\frac{2}{2-\beta}} .
$$

Equation (27) is a second-order polynomial. By inspection we find that the shape of the left-hand side is a symmetric parabola for which

$$
\arg \max _{t_{2}}\left(\bar{T}-t_{2}\right) t_{2}=\left(\frac{\bar{T}}{2}\right)^{2}
$$

The right-hand side is a constant larger than zero. If

$$
\frac{b}{A a} \frac{\beta}{2}>\left(\frac{\bar{T}}{2}\right)^{2-\beta}
$$

then there is no solution to (27), and if

$$
\frac{b}{A a} \frac{\beta}{2}=\left(\frac{\bar{T}}{2}\right)^{2-\beta}
$$

then there is one solution

$$
\left(t_{1}=t_{2}=\frac{\bar{T}}{2}\right)
$$

and if

$$
\frac{b}{A a} \frac{\beta}{2}<\left(\frac{\bar{T}}{2}\right)^{2-\beta}
$$

then there are exactly two solutions satisfying $t_{1} \neq t_{2}$.

\section{A.3 Proof of Proposition 1}

By lemma 1,

$$
\frac{b}{A a} \frac{\beta}{2} \leq\left(\frac{\bar{T}}{2-\beta}\right)^{2-\beta}(1-\beta)^{1-\beta} \text { and } \frac{b}{A a} \frac{1}{2}<\bar{T}
$$

are necessary conditions for an interior symmetric equilibrium when $0<\beta<1$ and when $\beta=1$, respectively. The interior symmetric equilibrium is supported by a positive price vector, which we denote $\left(\widetilde{w}_{1}, \widetilde{w}_{2}\right)$. 
By lemma 2,

$$
\frac{b}{A a} \frac{\beta}{2}<\left(\frac{\bar{T}}{2}\right)^{2-\beta}
$$

is a necessary condition for an interior asymmetric equilibrium, which is supported by another price vector which we denote $\left(w_{1}, w_{2}\right)$.

We want to prove that, when there exists an asymmetric equilibrium, then there also exists a symmetric equilibrium, i.e., that

$$
\left(\frac{\bar{T}}{2}\right)^{2-\beta} \leq\left(\frac{\bar{T}}{2-\beta}\right)^{2-\beta}(1-\beta)^{1-\beta} \quad \forall \quad 0<\beta<1,
$$

and

$$
(\bar{T}) \leq \bar{T} \quad \forall \quad \beta=1 .
$$

We prove each in turn. First, simplify (28)

$$
\left(\frac{1}{2}\right)^{2-\beta} \leq\left(\frac{1}{2-\beta}\right)^{2-\beta}(1-\beta)^{1-\beta} \text {. }
$$

Let

$$
L H S \equiv\left(\frac{1}{2}\right)^{2-\beta} \text { and } R H S \equiv\left(\frac{1}{2-\beta}\right)^{2-\beta}(1-\beta)^{1-\beta}
$$

We examine $L H S$ and $R H S$ for $\beta \rightarrow 0$ and $\beta \rightarrow 1$ respectively.

$$
\begin{aligned}
& \underset{\beta \rightarrow 0}{\operatorname{LHS}}=\frac{1}{4} \text { and } \underset{\beta \rightarrow 1}{\operatorname{LHS}}=\frac{1}{2}, \\
& \underset{\beta \rightarrow 0}{\operatorname{RHS}}=\frac{1}{4} \text { and } \underset{\beta \rightarrow 1}{\operatorname{RHS}}=1 .
\end{aligned}
$$

Hence, in the limits $R H S \geq L H S$. In order to study monotonicity, we first take logs:

$$
\begin{aligned}
& \ln (L H S)=(2-\beta) \ln \left(\frac{1}{2}\right), \\
& \ln (R H S)=(1-\beta) \ln (1-\beta)+(\beta-2) \ln (2-\beta),
\end{aligned}
$$

and then we take the derivative with respect to $\beta$ : 


$$
\begin{aligned}
& \frac{\partial[\ln (L H S)]}{\partial \beta}=\ln (2)>0, \\
& \frac{\partial[\ln (R H S)]}{\partial \beta}=-\ln (1-\beta)+\ln (2-\beta)>0 .
\end{aligned}
$$

Hence, both sides of (28) are monotonically increasing. Furthermore,

$$
\begin{aligned}
& \frac{\partial^{2}[\ln (L H S)]}{\partial \beta^{2}}=0, \\
& \frac{\partial^{2}[\ln (R H S)]}{\partial \beta^{2}}=\frac{1}{(1-\beta)(2-\beta)}>0 .
\end{aligned}
$$

We can thus conclude, that if an interior asymmetric equilibrium exists, then also an interior symmetric equilibrium exists for $0<\beta<1$.

Second, simplify (29) to get

$$
\frac{1}{2} \leq 1
$$

which is true.

\section{A. 4 Proof of Proposition 2}

From the proof of proposition 2, we have that an interior asymmetric equilibrium must satisfy

$$
\left(\bar{T}-t_{2}\right) t_{2}=\left(\frac{b}{A a} \frac{\beta}{2}\right)^{\frac{2}{2-\beta}}
$$

where $\bar{T}-t_{2}=t_{1}$.

Differentiate the right-hand side with respect to $A$ to get

$$
\frac{\partial\left(\frac{b}{A a} \frac{\beta}{2}\right)^{\frac{2}{2-\beta}}}{\partial A}=\left(\frac{b}{a} \frac{\beta}{2}\right)^{\frac{2}{2-\beta}}\left(\frac{2}{\beta-2}\right) A^{\frac{2}{2-\beta}-1}<0,
$$

which means that an increase in $A$ shifts down the right-hand side of (30).

The left-hand side of (30) is an inverted "U-shaped" parabola, and therefore the distance between the values of $\left(\bar{T}-t_{2}\right)$ and $t_{2}$ which solves the system increases as $A$ increases.

The wage gap is given as a function of $t_{1}$ and $t_{2}$ by (10):

$$
\frac{w_{1}}{w_{2}}=\frac{t_{2}}{t_{1}} \text {. }
$$

The more $t_{1}$ and $t_{2}$ differs, the higher the gender wage gap. 